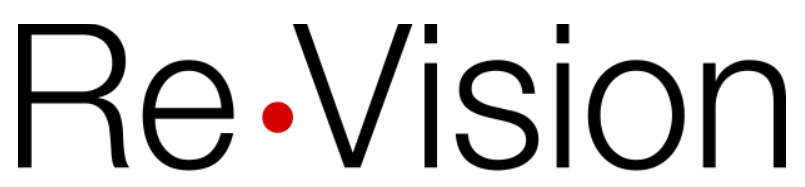

UNIVERSITY

The Centre for Art and Social Justice

\title{
Making spaces: Multimedia storytelling as reflexive, creative praxis
}

Carla Rice

University of Guelph

Andrea LaMarre

University of Guelph

Nadine Changfoot

Trent University

Patty Douglas

Brandon University

This is an Accepted Manuscript of an article published by Taylor \& Francis in Qualitative Research in Psychology on March 27, 2018, available online: https://www.tandfonline.com/doi/full/10.1080/14780887.2018.1442694

\section{Recommended citation:}

Rice, C., LaMarre, A., Changfoot, N., \& Douglas, P. (2018). Making spaces: Multimedia storytelling as reflexive, creative praxis. Qualitative Research in Psychology.

https://doi.org/10.1080/14780887.2018.1442694 


\section{Making spaces: Multimedia storytelling as}

\section{reflexive, creative praxis}

Carla Rice, Andrea LaMarre, Nadine Changfoot \& Patty Douglas

\section{Abstract}

In this article, we explore our experiences as researchers and participants in multimedia storytelling, an arts-informed method wherein we work with artists and aggrieved communities to speak back to dominant representations through film. In positioning ourselves as storytellers, we do research with rather than "on" or "for" participants, allowing us to connect in practical and affective ways as we co-create films. Drawing from dialogues about our workshop experiences, we outline four themes that make the storytelling space unique: reflexivity; structure and creativity; transitional space and reverberations; and fixing versus being/becoming with. We analyze our self-reflexive films on mind-body difference as "biomythographies," as films that situate stories of ourselves in technological-temporal-spatial relations and that highlight how we make/experience change through creative research. Multimedia storytelling, we argue, allows us to enact reflexive creative praxis in a way that opens to difference rather than trying to fix it, forging an ethic we find all too rare in the neoliberal university.

\section{Keywords:}

Biomythography, collaborative research, disability and difference, feminist research methods, multimedia storytelling, posthumanism

To watch the stories presented in our paper, go to https://projectrevision.ca/makingspaces. Following the prompts, type in the password "spaces." Please note: these videos are intended for readers only and are not for public screening. 


\section{Introduction}

Since the 1980s, feminist and critical researchers have called for methodological shifts that allow us to work more deliberately, consciously, and meaningfully with participants 1 (Rice 2009, 2017). We use the term participant to denote those who collaborate in our research; however, we also consider ourselves to be participants in our research, particularly in the context of the work discussed in this article. We retain the terminology of participant in order to insert this work into the qualitative paradigm we are speaking into, working to redress researcher-participant power relations from within. Reflexivity is now firmly ensconced in our scholarly lexicon and is sometimes used, ironically, without reflection. That we must turn the gaze on our positionalities to understand how we interact with participants and analyze our data is nearly taken for granted, at least in poststructural and other critical academic spaces. Reflexivity and similar terms associated with academic feminism in 2017 (e.g., subjectivity, intersectionality) are often used haphazardly, suggesting that we might name our privileges, oppressions, and belongings and be done with them; move on and do the "real" work, productive neoliberal subjects that we are. The uptake of reflexive praxis has not been accompanied by shifts in policies from journals and other research repositories, in which word limits place restrictions on researchers' abilities to report reflexively on their research. Feminist academia, which some argue is an oxymoron (Stacey 2000), has been instrumental in drawing attention to the need to implicate gender (and, later, other intersecting locations) in research if we wish to understand social phenomena. Yet beyond identifying where we each belong in relation to these locations and to our subjects of analysis, there are fewer examples of feminist academic spaces that allow us to break down entrenched hierarchies between those involved in research processes, generally termed researchers and participants, implicate ourselves (in all of our complexities) in our research, and explore not only our shifting spaces of belonging but also the deeply affective character of our research. There are even fewer spaces in which we can examine the ways that our research shapes us.

\footnotetext{
${ }^{1}$ We use the term participant to denote those who collaborate in our research; however, we also consider ourselves to be participants in our research, particularly in the context of the work discussed in this article. We retain the terminology of participant in order to insert this work into the qualitative paradigm we are speaking into, working to redress researcher-participant power relations from within.
} 
In the research arena, much of the resistance to the kind of deep engagement required to enact (rather than simply give lip service to) reflexivity can be linked to the demands of neoliberal academia, including appeals to quantification and evidencedbased data, time/funding constraints, and impacts and results frameworks. Engaging in methods and practices that demand both time and space for reflection on thorny questions of who we are in relation to our research becomes more challenging when we are expected to perform and prove our (numerically defined) productivity by meeting external criteria for publications, teaching, and service in the neoliberalized academy. We are far from the first feminist academics to comment on these problematics or to suggest methods for circumventing them (Baer 2014; Nah 2015; Taber 2014).

In this article, we reflect on the multimedia storytelling method as counterpractice to the practices of the neoliberal university-a way of doing social science research as arts-based, feminist praxis. This method allows us to unsettle the researcher/participant hierarchy and to extend our analyses beyond the empirical to engage with the theoretical insights of the (post) humanities. We envision the storytelling space as a temporary community of participants and researchers working together to generate alternative possibilities for living (Rice, Chandler \& Changfoot 2016). Rather than doing research on or even for our communities of interest, we do this research with participants in a way that allows us to connect with them in emotional and personal-political ways as we create short films about their (and our) experiences. To surface the affects and effects of arts-based research processes, we present insights from dialogues between one another about our experiences of multimedia storytelling workshops. We explore and deconstruct our artistic outputs, microdocumentaries that we created in these workshops, as "biomythographies" (Lorde 1982), films combining elements of history, biography, and myth (in the sense of a powerful cultural and psychic idea) that situate stories of our "selves" in broader technological-temporal-spatial relations and that highlight how we both make and experience change through the creative research processes we collaboratively undertake. 


\section{Creating spaces for reimagining selves}

Social science research has been slow to engage with poststructuralist theories on subjectivity that burgeoned with the linguistic turn in critical thought (see Gannon \& Davies 2006). Writing against the grain, feminist researchers and writers since the 1980s have developed and adapted critical theory, including poststructural, queer, crip, and critical race theory, to create new accounts of subjectivity in/as difference (see, for a review, Gagnier 1991). Some critiqued normative notions of the subject that underpin Western canonical thought since the Enlightenment-that introspective, autonomous, rationalist, and disembodied (white, nondisabled, heterosexual, masculinist) norm, commonly assumed to be the ideal of the species-to open theoretical space for centering subjectivities marked as different (Braidotti 2013). Others explored subjectivity as continuously differentiating in its nonlinear, multiple, embodied, shifting, and relational formations and transformations, and in its becoming via flux and change (Grosz 1994).

Black, lesbian, disabled poet-activist Audre Lorde occupies an important place in the feminist (anti)canon, in part for her re-invention of life writing. She calls her autobiographical Zami "a biomythography," and in so doing creates a new genre that reconfigures autobiography and mythology to open a "larger space for her myriad selves" (Alexander, 1994, p. 696). She begins her memoir with the dedication, "To the journeywoman pieces of myself. Becoming. Afrekete" (1982, p. 5). She ends by "[r]ecreating in words the women who helped give me substance...[including] Afrekete, her youngest daughter, the mischievous linguist, trickster, best-beloved, whom we must all become" (p. 255). This bookending suggests that most important to Lorde is the West African trickster, Afrekete. Drawing from the trickster's cultural associations with unpredictability, sexual transgressiveness, and gender fluidity, Lorde imbues her guiding figure with "linguistic skill and black female strength, intelligence, and sexuality," repeatedly returning to its "heterogeneous identity and ability to communicate, connect, and survive despite (because of) difference" (Provost 1995, pp. 46-7). The multivoiced trickster becomes a shapeshifting entity who refuses a singular or settled identity, but instead walks the line between various groupings/belongings, finding creative ways of speaking into existence a polyvocal self that is ever becoming. Guided by Afrekete, 
Lorde imagines her becoming self as "blackened and whole" (1982, p. 5), simultaneously male and female, othered and empowered, apart and a part, enabling readers to reframe differences in others and ourselves as ties that both free and bind us.

Our digital media saturated age, distinguished by the widespread online sharing of personal stories, represents another key moment in the constitution/theorizing of subjectivities (Hayles 1999). Engagement with digital technologies marks a posthumanist shift away from "man" as the measure of all things toward more expansive conceptions of humanity, including of subjectivity as a "construct that emerges in concert with technology" (McNeill 2016, p. 66). A downside to this development is that most of us access the Internet through corporatized digital spaces that constrain the kinds of self-narratives we can construct. However, feminist adaptations of these spaces also create possibility for new imaginings of subjectivities, enabling a proliferation and affirmation of differences. Through diverse digital platforms, including feminist blogs, Youtube videos, and Instagram accounts, users stage posthumanist interventions into the feminist autobiographical form (Barounis, 2016; Kang 2016), enabling the construction of preferred stories of identities/selves. These genres/platforms can be understood as visualizing and collectivizing biomythography in the ways that they offer users a repertoire of image, myth and history from which to cocreate self-stories and give politicized communities access to new spaces for intersectional self-invention and narration (Baer 2015).

In a similar vein, we consider the multimedia storytelling workshop to be a creative, reflexive space for critical self-narration/revision, including for ourselves as researcher-participants. Transporting us beyond the confines of our previously known selves and the simplicities of the categories into which we are inscribed, multimedia storytelling can be conceived as a process of auto-poesis (self-creation/self-becoming; Braidotti Braidotti 2008) in an expansive community space that allows us, as storytellers, to explore the liminalities, marginalities, and privileges as well as uncertainties and changeabilities of our bodily selves and lives. This concretely breaks down the participant-researcher binary by exposing the illusion of researcher impartiality. "The identities created within/through digital stories can be fractured, 
multiplicitous, unpredictable, paradoxical, and fleshy... They may also provide elucidative strategies through which one can come to embrace the posthuman, or at least reject the (humanist) human" (Rice et al. 2016). Though multimedia stories may appear less "complete" or "final" than other research outputs, we have found they allow us to craft rich visual narratives of our personal/political worlds, inviting us to engage autoethnographically in a context of accountability to a larger community. Beyond written narratives, these biomythographies capture aspects of selves via facial expression, body gesture, tone of voice, choice of imagery and sound, and so forth that transcend the linguistic.

In the genealogy of feminist storytelling, we see processes of multiple identifications culminating in feminist poststructuralist and posthumanistic theories of the subject. While autoethnography, within this genealogy, might be understood as a critical method that combines autobiography with ethnography and connects personal with cultural experience (Ellis, Adams \& Bochner 2011) and self-reflexivity as an analytic tool for interrogating how researcher positionality shapes research processes, biomythography may be considered as an artful approach to self-invention/narration that weaves together history, biography, and imagination in the re/telling of lives. Like Lorde and feminist storytellers who have followed her, we view multimedia stories as evocative snapshots of our shifting, entangled subjectivities and social worlds created in equity-attentive workshop spaces. In these spaces, we augment our personal stories with history, myth, and image, moving beyond dualisms of private and public, story and history, text and image, researcher and participant, and past and future to surface/create/tell who we become in relation through our research. Just as Lorde deployed "storytelling to comprehend, resist, transform, and heal from patriarchies, racism, and various oppressions to explore uncharted journeys" (Hua 2013, p. 31), we make stories to surface and resist the fractures and sutures of various oppressions we confront/witness and use them both with and as participants to confront our privileges even as we author/revise ourselves as (differently embodied) feminist researchers. 


\section{The multimedia storytelling space}

We have used multimedia storytelling to explore diverse lived experiences with/as participants and researchers, including disability/difference, autism and inclusion, Indigeneity and schooling, eating distress and weight stigma in queer community, and more. We conduct our work through Re•Vision: The Centre for Art and Social Justice at the University of Guelph, a social science research hub that uses artsinformed, community-engaged research to foster inclusive communities, well-being, equity, and justice in Canada and beyond. Our media arts laboratory, REDLAB, provides state-of-the-art computers and other technologies required for filmmaking. Our workshops have been diverse in approach and in participants; some workshops have been explicitly oriented toward research reflexivity, some have been conducted in the context of specific research projects aimed at exploring social phenomena, and some have been open to members of the public and particularly the research community interested in learning the method. We have evolved a research apparatus to frame our workshop methods, innovated iterative accessibility/inclusion practices, and engaged with multimedia storytelling in a way that we think of as improvisational; that is, we adapt the process to the needs and interests of the groups with whom we work, and we think artfully and critically about the representational field relevant to each group. While we ground our work in community-facing filmmaking methods, we recognize that epistemologically and methodologically, the work of centring marginalized voices comes from a much longer lineage connected to critical psychologies, decolonizing movements and feminist methodology among others (for more information on method see, Rice, Chandler, \& Changfoot, 2016, Rice \& Mundel forthcoming).

Each of the authors of this article has participated in and facilitated storytelling workshops. These have ranged from one to five days, featured original presentations on the representational field into which the specific study is intervening (often co-developed by researchers, independent artists, and artists who are also graduate students) and included group-tailored tutorials on the fundamentals of photography/videography, video editing, and creative writing. Participants' artistic outputs are two-five-minute-long videos that pair audio recordings of personal narratives with visuals (e.g., photographs, videos, artwork). The composition of workshops varies based on the intent and the key 
players; equally, participants (including researchers, artists, and community members) take part for various reasons. Some participate to learn about the method while others are interested in exploring experiences; often people have multiple reasons for participating, including these and other reasons, such as opening up the representational field related to spaces of marginalization they may be experiencing. After reflecting on Re•Vision's five-year involvement in the storytelling world, Carla Rice and doctoral candidate Andrea LaMarre began speaking with our co-authors on this piece, Nadine Changfoot and Patty Douglas, about what makes the storytelling space unique. LaMarre spoke with each of the co-authors about their experiences; conversations were loosely structured around what co-authors had learned about themselves, their topics of research interest, and the storytelling method through engaging in the method with/as participants.

Based on these conversations and collective dialogue on the storytelling space, in what follows we discuss the major insights that surfaced: reflexivity, structure and creativity, transitional space and reverberations, and fixing versus being/becoming with. To deepen our discussion, we punctuate these themes with analyses of our selfreflexive stories as biomythographies, asserting they creatively engender posthumanistic becoming subjectivities or subjectivities that disrupt the idea of the human as rationalist, disembodied, able, and useful (under neoliberalism). We further argue that the stories destabilize the idea of the researcher as (dis)interested bystander and researcher-participant hierarchies by surfacing not only how our subjectivities shape our research processes but also how those processes inevitably shape us.

\section{Reflexivity}

We see reflexivity as neither a laying-out-and-forgetting-about our spaces of belonging (a view that treats identity categories as additive variables) nor as a way of suggesting that we can ever possibly know the embodied experiences of the Other (Rice 2009, 2017). For us, in the position of storyteller participant-researchers, the storytelling space has felt like a space of shared purpose and community. It has allowed us to explore our positionalities in ways other than writing about them theoretically, inviting us to interrogate our subjectivities in the same way as we ask participants. The stakes are not the same for researchers and for participants, however; we know "the 
rules of the game" even if we subvert them, and we can choose to subvert them. This doesn't make the work less risky, but it is risky in a different context: risky in certain scholarly circles that frown upon sharing personal stories; risky in how we've been told "that's a great story... but you shouldn't tell it again," and "I'm not sure why you'd put your pain on the screen for others to consume." We push against norms that ask participants to tell vulnerable stories but discourage researchers from doing so for fear of loss of reputation or prestige, or for imputing bias into research outputs. Exploring what happens in the storytelling space itself can feel vulnerable and sometimes raw particularly because each time we engage in storytelling, there are aspects that we cannot anticipate and that perplex us on subjective, methodological, and theoretical levels. When we engage reflexivity in this way, we unearth our complex entanglements as researcher-participants. The reflexive, art-making space enables us to attenuate hierarchy between researcher and researched and offers us a moment to explore the meaning of doing improvisational, creative feminist research that pushes back against neoliberal academia. We also recognize that participants may not experience the same vulnerabilities and/or enjoy the same protections we as (tenured and untenured) scholars do. For this reason, we think carefully about each representational field we are talking back to as we prepare workshop curricula and open up frank conversations about possible effects of the stories that participants (including ourselves) decide to tell.

This suggests that who is in the room matters. We each occupy different places in terms of privilege and marginalization; these spaces of belonging impact the extent to which we are able to make ourselves vulnerable, and to whom. While our workshops are generally oriented around a single topic, at times, combining issues has led to unexpected cross-pollination of issues that has enriched discussions. We found that more than group membership, participant and researcher willingness to "go there" with the issues matters. This does not mean that we ask all participants to go to places of vulnerability; not everyone lays themselves bare in their stories. However, there is permission in the space to tell whatever story compels you on that day. As Nadine puts it: "I have this story that I haven't shared with anyone ... I know it is holding me back, but I can't describe exactly how." Often participants have found that knowing that others 
want to hear their story is motivating - we try to make space for the story to be heard, whatever that story is.

Participation in research on changing conceptions of disability started Nadine on a "Lordesque" journey that continues to inform her examination of the now recognized and still hidden edges of her embodied history. Her video (https://projectrevision.ca/making-spaces password: spaces) opens with a photo of Nadine as a young child narrating that "mind and body were not separate: mindbody was one field of happiness ever-expanding...in flowing connection with playmates." She did not see or feel her body as racialized until childhood friends declared it so: "Yellow skin.' 'Slanty eyes.' 'Flat nose.' 'Chink.' In the film's second scene, she recounts times when her adult self is asked the question "Where are you from?" and then, when unsatisfied with her answer, her interlocutor presses, "Where are you really from," she is once again reminded of bodily markers that disqualify her of her Canadianness. For Nadine, storying these experiences required a community of differently-positioned witnesses. Through connecting with others' stories and experiencing them connect with her own, Nadine found it possible to infuse new meaning into a past haunting. She began to recognize a profound vulnerability at the heart of racializing and disabling processes: this vulnerability, produced through standards of personhood that have rendered disability and race as inferior and physical/mental defect, pushes people into dis-identifying with both categories in a bid to qualify as human. For the first time, Nadine understood how the academy's ableist (and racist) standards required her to downplay race and disability in order to avoid being interpolated as deficient. For example, when applying for tenure, she was privately advised not to call attention to her positionality of race or role as carer for disabled parents. Since making her video, Nadine has shifted her research focus from European feminist and political theory, dominant in her discipline of political science, into critical disability and aging studies as she becomes aware of her multiple selves.

\section{Structure and creativity}

In our dialogues, we also reflected on how we inevitably fail to organize workshops that are completely accessible to all bodies at all times (Rice et al. 2014). Through various workshops in which we have often failed to anticipate the needs of all 
participants, whether those needs are for physical accessibility or ideological openness to varied perspectives on politically charged issues in which we all hold stakes, we recognize that accessibility is more than a checklist. The check boxes exist here, too: Is there space for wheelchairs? Are sensory considerations like low lighting and quiet rooms available? Are there gender-neutral washrooms? Are the chairs comfortable for diversely sized bodies? But more than these tick boxes, in each workshop we have encountered different expectations and understandings of the dynamism that disability and embodied difference bring. Our research practice has been impacted by this realization, in part through our acknowledgment of how we need to be prepared for the unexpected and nondefensive in our reactions to our failures. Explicitly and from the outset, we center difference, which we welcome in its unpredictability and dynamism. Still, we can, have, and will encounter challenges in making our spaces work for everyone, making the storytelling space improvisational and provisional; it is different each time, imperfect and shape-shifting, continuously moving and negotiated in relationship with who is present in the room.

Perhaps the best example of improvisation is time. Within each workshop, different relationships to time are embodied and enacted alongside and in tension with one another and the storytelling process. Sometimes, a nine-to-five schedule is not workable for all participants, facilitators, and artist supporters. Though people who arrive "late" might appear to be less engaged, seen differently we might consider the late arrivers not as claiming preferential treatment but rather as inhabiting spaces of time differently. Opening to different ways that time might be inhabited welcomes difference in and pushes back against neoliberal logics that demand productive "on time" (not-tooslow-or-too-fast) body/minds. At the same time, remaining "on time" in terms of workshop agendas is crucial for some participants to access the creative process even as the process is a collaborative negotiation of time/space. Negotiating time accessibility is less about privileging one person's needs above another than about negotiating how we might push the boundaries of how we work together in ways that enfold embodied difference and different ways of belonging. A full exploration of the nuances of time is beyond the scope of this article and warrants its own theoretical engagement. Reflecting on our storytelling experiences, however, we note the 
complexity of time in relation to story and accessibility; the flows in and out of time, loss of time, "sticking to" time, and storying oneself in time are all complex processes of envisioning and revisioning who we are in relation to normative and asynchronous temporalities. Arguably more than in traditional methodologies, these temporal tensions surface in the structure and flow of storytelling. The storytelling method simultaneously pulls us out of time, that is, into a workshop context where we focus on creating a narrative in (usually) three days, and transports us into other timescapes and into "creative time" that pushes against pressures for faster production of outputs within the neoliberalized academy.

Constraints are, to a certain extent, necessary. A tension exists between our ideological commitment to multiple belongings in our workshops and the nonlinearity of time, and to the structures that impose normative temporal ways of working and being together. Rogoff (2013) comments on a problematic tendency to self-congratulate when we develop arts infrastructure; while such infrastructure opens up the possibility of creation, it may also lead to protocols that confine creativity. With this challenge, we might consider how we have attempted to play with structure and time in ways that establish the workshops as playful, creative, nonhierarchical, and nonlinear spaces. For example, we played with time in a workshop series on autism and inclusion, where failure to stick to normative time, that is, finishing your story, attending to or departing from schedules, was folded into the workshop design after Patty consulted with participants about access. In this workshop, we also played with sensory access, rethinking ways to be together (and apart) in the workshop space-having fiddle toys on hand, slowing time down to speak with non-speaking participants who type or write, inviting movement(s) into and out of group activities, changing the physical shape of the story circle (where participants share story ideas) to relieve normative social time, and pre-recording a tutorial and access guide about the workshop. Hlavajova (2015) describes this as "instituting otherwise"-pushing up against broader systemic confines while maintaining a shared focus on the arts as a space of great potential. Despite this playfulness, we also face the demands of neoliberal academia; these playful spaces and products are bound into academic outputs, including this and other journal articles, perhaps jeopardizing the sense of freedom they ostensibly scaffold. 
Negotiating constraint varies each time and emerges from who is in the room. Honouring the difference and Otherness in each of us while also navigating bureaucracy, for instance, negotiating degrees of consent and release with institutional research ethics boards and other constraints, for example, everything from securing room bookings to performing to traditional research metrics, -can feel like an abrupt rub. Every time we design a project, we think about what people need and want and require to create their stories as well as how much we can give as researchers. Though it would, in one sense, be desirable to offer a prescription for the perfect multimedia storytelling project, we explicitly avoid doing so; if we really want to bring difference in, we must attend to the wrinkles difference brings and embrace the messiness of improvisation as central to our research process. At times, this means seeking out journals that are willing to accept manuscripts with videos embedded or that reject a traditional qualitative analysis, opting instead for case study or alternative formats, which may carry with it implications for publishing in "prestigious" journals. Multimedia storytelling, as we see it, requires a full scale of skills, including the awareness that perfection, as defined by general social productivity standards and in neoliberal academia, is illusive. Navigating the tension between creativity and neoliberal metrics has been an ongoing challenge as we have attempted to negotiate and play with structures within academia that feel at times inaccessible and stifling: we need to be both cautious and revolutionary, which is not an easy rub. Our ongoing negotiation of this tension has led to us becoming both pragmatic and innovative, for instance, finding ways to publish both in mainstream journals and screen films at film festivals, working relationality into ethics forms and procedures, disclosing about ourselves and our spaces of belonging with participants, co-authoring with nonacademic participants, establishing DOls for films to include them as outputs on resumes, and engaging in transdisciplinary scholarship and with the arts. Finding researchers across universities and in other sectors who share a commitment to inviting in difference and creativity with whom we can navigate this tension has been a crucial step in building community and helping us to renew and continue our commitment to these projects.

Workshop structures emphasizing access and play supported Patty to make her biomythography Walking the Lines (https://projectrevision.ca/making-spaces password: 
spaces) while she was still a doctoral student researching autism and mothering. Juxtaposing familiar scenes (making breakfast, calling to her son to get ready for school) with a computerized phone message reporting her autistic son's daily absences, Patty explores her failure to get her sons to school "on time." Academic disability studies spaces and approaches helped Patty re-think autistic difference positively as well as their implication within neoliberal care regimes. Yet, given political and academic divides between disability communities and mothers/carers (Ryan \& Runswick-Cole 2009), her story of disablism as a single mother alongside her autistic son, and as an ambivalently disability-identified woman/mother survivor of structural violence, remained submerged. The structure of the storytelling workshop opened space and generated safety for Patty to explore her history and biography of multiple and contradictory belongings. Not being "on time" became about access rather than failure, pushing back against mothering in the service of neoliberal ableist schooling or academia. Witnessing another mother celebrate her ambivalent disability story with her child supported Patty's own risk-taking in the workshop. The workshop process initiated an artful exploration for Patty of her history, biography and multiple contradictory belongings that arguably could not have surfaced within other academic spaces or approaches. This process continues to reverberate in storytelling workshops and research on autism and education Patty now facilitates, pushing back against neoliberalized academia's impingement on her creativity, improvising access and sharing her stories with participants to mitigate researcher-participant hierarchies, enacting collaborative research to bridge community divides, and planning concrete interventions together with participants (i.e., co-facilitated professional development forums) into specific fields such as teacher education using videos made in workshops together. This is perhaps an example of what Hlavajova (2015) meant by "instituting otherwise."

\section{Transitional space and reverberations}

In many ways, engaging in multimedia storytelling has encouraged us to be bolder and work differently in other areas of our lives, for instance, breaking down traditional hierarchies through bringing vulnerability and openness into the classroom by sharing our stories and inviting students to do the same. While the movement from the workshop space back into conference presentations and paper writing can feel jarring, 
we reflect on this encounter, too, as a movement from one aspect of our embodied experiences to another. Performing our roles as academics requires shaping our experiences, which are often embodied, into palatable, or at least intelligible, forms for academic consumption, which contributes to the discordant nature of this move. In not splitting off the storytelling space from the rest of our lives we also think about the many ways we work in our lives and live in our work. Sometimes creativity comes when we let our guard down - when taking a shower, baking muffins, reading a novel, or driving a car. The rhythm of our lives is process-based and unending; as Patty described it, it is like the laundry cycle; it unfolds in pauses and starts, cycling around again without ever really stopping. Recognizing these flows and pulls encourages us to reconsider what the experience of research can be like for participants. It helps us stay aware of how the subjects about which we ask participants are not parsed out from the remainder of their lives; far from it, their experiences are all tied together into their "lived experience" writ large. While there is a pull to develop work-life balance in and beyond academia in order to manage the demands of conducting emotionally charged work, and we recognize the utility of boundaries in protecting ourselves and our time, we have found that this boundary creation is often messier than it may appear.

There are specific facets of the multimedia storytelling space that make it powerful; the power of the spaces lies partly in their possibilities and the willingness of those in each space to engage with the messiness of not-arriving, not reaching a perfect destination and wrapping things up in a bow as neoliberal logics would have us do. Unlike other academic spaces, we welcome in all of ourselves and all of our participants; we invite a transversal politics throughout the process rather than only in analysis ("transversal" in that we recognize through our workshop structures and curricula the inter-group histories and relationalities of those re-storying the issues). Carla noted that this is not a Pollyanna-esque future perfect, but rather a collective investment in holding together a space that allows for human connections. Andrea reflected, in one of our conversations together, that this sense of "I value who you are as a human, in all of your difference from me" can be taken into the world. We understand participants not as "research participants" only, but as human beings who occupy various positions in the world. This orientation exemplifies how our research can 
push outward into understanding the role of the researcher as another human seeking not the pragmatic value of a research input, but the connection with self and Other.

Carla's video Through Thick and Thin captures how storytellers can explore and fail to resolve difficult life problems (and perhaps inevitably so given the extent to which they are socially produced) while still celebrating the material and spiritual joys of living and creating in response to them (https://projectrevision.ca/making-spaces password: spaces). In the video, she explores her embodied subjectivity as process, reflecting on her body history as a visceral exploration of how discourse becomes lodged in the flesh. Desire/disgust and beauty/ugliness interweave through the story of her body's metamorphosis, refusing finality and closure. The story's imagery comprises a series of black and white close-up photographs of Carla's body in the present. Some appear to be taken from an outsider's perspective, and others evoke intimate embodied memories of a person looking down at their (or a lover's) flesh. The images focus on the textures of her skin over bones, muscles and fat: smooth and ornamented, relaxed and folding, wrinkled and puckered. The split relationship with her body suggested by her narrative and images might be understood in line with Lorde's own depiction. While Lorde recounts traumatic experiences such as racism and sexual assault, she also foregrounds sensuous, empowering memories, reminding us of the importance of what Anh Hua calls "the ethics of pleasurable feminism, that is, the reclamation of female embodiment, female pleasure, and female sensuality as an activist sacred site to counter the patriarchal, racialized, and heteronormative oppressions that so many women experience in our daily lives" (2015, p. 113). Beyond teaching her that she has not fully resolved her own body struggles, making this video has taught Carla how creative processes can offer different insights/answers to social problems than therapeutic or theoretical ones. Translating her embodied struggles through art freed Carla from her clinical mindset that psychic struggle signifies something is broken and needs to be fixed, and from her scholarly one that meanings of psychosocial problems are best made through theory. The art-making process further allowed Carla to experience how artistic processes can create catharsis and transformations that reverberate across multiple areas of her life, helping her to discover that it is still 
possible to find acceptance, and even resolution, through dwelling affirmatively in the contradictions.

\section{Fixing versus being/becoming with}

Particularly as our research often centres around psychological and physical phenomena, we've often been asked the question, but aren't you doing art therapy? It is here that we make a strong distinction between arts-based research and art therapy; this difference coheres around the difference between fixing and being/becoming with. That is, the therapeutic space is different in its orientation to finding solutions and a framework that will solve or fix the difference with which the client presents. Further, the therapy space is often individual-based or dyadic, as a therapist imparts their expertise and allows the client to share their story while offering new ways and solutions of working through distress, focusing on difference as problem.

Our method is inherently inter-relational, not individual, and not about finding solutions: building collectivity is central to the filmmaking and storying that goes on in and beyond the space. Others are present in the space, witnessing the story, welcoming the difference, envisioning and enacting new possibilities (of meaningmaking and agency), and perhaps even offering new ways of telling the story. At the workshop's end, there is a story crystallized on the screen-a story we frame as an intentionally constructed visual narrative that is not a permanent account of one's life but instead a sustainable imprint of the story that needed to be told at that particular moment on that particular day with those particular people.

When we focus in on the importance of collectivity and state that "who is in the room matters," we refer not to the idea that all people need to share goals or experiences, but that a necessary condition of fashioning the storytelling space is a shared commitment to collective engagement. This includes individuals composing their own biomythographies and a community co-creating interventions into the representational field. The story circle, and subsequent interactions, are imbued with multiple desires-desires that fluctuate over the course of the workshop and are not necessarily shared at all times by all participants and/or facilitators. These include desires to express, to name submerged experiences, to struggle together and in community, to understand one's own relation to the phenomena being explored, to 
engage with an ethic of telling, of being together, with oneself, and with others. Instead of problematizing different desires, we center and value difference; this centering of difference is not common in academia, and is a profoundly affecting experience that both terrifies us and feeds our work. A quote from Carla illustrates this tension:

"I have a strong desire to understand difference even as I know that this is impossible... I do believe that it is entirely possible to get closer to, and to understand my fear of, difference. My stance is not fearless but my curiosity is bigger than my fear, and though my fear sometimes hurts people I refuse to allow it to hurt people in an ongoing way as I walk through the world."

Andrea's story speaks to the ways in which participants can assist us in pushing our stories beyond neatness and into complexity (https://projectrevision.ca/makingspaces password: spaces). In it, she speaks back to a film she made early in her exploration of the storytelling method and in which she replicated certain "told" stories of eating disorder recovery. In this story, Coda, she removes the punctuation from the end of the "recovered" sentence, not as a way of re-inserting herself into the grips of distress around food, weight, and shape, but as a way of troubling the clean lines between pathology and wellness. She asks questions in the voiceover, inviting the audience to re-consider the finality of the state of recovery with her, and leaves the story unresolved. She also chooses fewer images of her body, electing instead to focus on aspects of recovery unrelated to physical form. In the two years in between her first and second stories, Andrea changed her stylistic and theoretical approach to storytelling, a metamorphosis that continues to impact her approach to the method.

Coda also invites us to consider how the stories we make are never fixed in time, whether they are "recovery" stories or not. It does so not only in content but in its creation. By making Coda, Andrea named her previous story as unfinished, revealing the ever-moving nature of subjectivity and the intertwinedness of recovery and growing up. When she made her initial film, Recovered, Andrea was leaving undergraduate education, and yet to discover critical theory in any depth. Throughout her graduate education, Andrea changed not only her orientation to recovery but to life; through 
learning about how openness and complexity can be a gift rather than a problem, she became able to theorize recovery as incomplete and continual without assuming that to

do so means being "less than." Just as Coda reflected back on her changing subjectivity and growing up, it too is reflective of a moment in time; Andrea's subsequent stories have allowed her to revision who she is in relation to this work. Through engagement with research participants, Andrea's recovery became something different; something more open to difference.

\section{Conclusion}

We have no real "solutions" for how to standardize into method our insights from this kind of generative work in the neoliberalized academy. We, too, have struggled with the metrics and measures we are asked to live up to daily, and the call to be impartial and objective or to treat reflexivity as a concept that we name but don't enact in any meaningful way, lest we be seen as biased or less than. Yet telling our stories has been an instrumental part of asking participants to do the same. Our participants are our collaborators and our communities-we are a part of (some of) the communities to which they belong and they are a part of (some of) the communities with which we affiliate. They offer us insight into their (and our own) experiences in a way that allows us to centre difference and reveal the complexities of power, shaping us in ways that provide insights for new possibilities for living otherwise. It is our assertion that centering difference through a reflexive, creative praxis - which, as Braidotti (2013) articulates, is embodied, embedded, and accountable_opens moments of being/becoming together differently that push back against the normalizing constraints of neoliberal academia. Polyvocalities, corporeal and submerged embodied histories and positionalities, and unresolved desires, endings, and tensions emerge that provide proliferating complexity and richness of becomings. Within multimedia workshop spaces, the tools and skills necessary to resist and transform hierarches of difference and researcher/researched divides are discovered together in ways that might be taken beyond the storytelling space, for example, through co-authored publication with nonacademic participants and inviting non-academics to screen their videos with researcher-participants. By selfreflexively implicating our own subjectivities as researchers, we excavate/surface the 
rationalist, disembodied humanist subject that fixes researcher-researched hierarchies and haunts feminist and critical research agendas. This makes the risks and vulnerabilities of centering difference and our own becoming subjectivities in our work, which often rubs up against institutional structures in challenging ways, worth it.

\section{References}

Alexander, E 1994, '“Coming out blackened and whole": fragmentation and reintegration in Audre Lorde's Zami and the cancer journals', American Literary History, vol. 6, no. 4, pp. 695-715.

Baer, $\mathrm{H}$ 2014, 'Redoing feminism within and outside the neoliberal academy', Women in German Yearbook: Feminist Studies in German Literature \& Culture, vol. 30, pp. 197-208.

Barounis, C 2016, 'Alison Bechdel and crip-feminist autobiography', Journal of Modern Literature, vol. 39, no. 4, pp. 139-61.

Braidotti, R 2013, The posthuman, Wiley \& Sons, New York.

Braidotti, R 2008, 'Of poststructuralist ethics and nomadic subjects', in M Düwell, C Rehmann-Stutter, \& D Meith (eds.), The contingent nature of life: bioethics and the limits of human existence, Springer Press, Dordrecht, pp. 25-36.

Ellis, C, Adams, T \& Bochner, A 2011, 'Autoethnography: an overview', Historical Social Research/Historische Sozialforschung, vol. 36, no. 4, pp. 273-90.

Gagnier, R 1991, 'Review: feminist autobiography in the 1980s', Feminist Studies, vol. 17 , no. 1 , pp. $135-48$.

Gannon, S \& Davies, B 2006, 'Postmodern, poststructural, and critical theories', In S Hesse-Biber (ed.), Handbook of feminist research: theory and praxis, Sage Publications, Thousand Oaks, pp. 71-106.

Grosz, E 1994, Volatile bodies: toward a corporeal feminism, Indiana University Press, Bloomington.

Hayles, N 1999, How we became posthuman. Virtual bodies in cybernetics, literature, and informatics, University of Chicago Press, Chicago. 
Hlavajova, M 2015, On the present Zeitgeist and the position of the artist, Speech at the "Honger naar radicaliteit. Dood aan de nuance" project De Theaterschool, Amsterdam.

Hua, A 2013, 'Black diaspora feminism and writing: memories, storytelling, and the narrative world as sites of resistance', African and Black Diaspora: An International Journal, vol. 6 no. 1, pp. 30-42.

Hua, A 2015, 'Audre Lorde's Zami, erotic embodied memory, and the affirmation of difference', Frontiers: A Journal of Women Studies, vol 36, no. 1, pp. 113-35.

Kang, N 2016, 'Audre's daughter: black lesbian steganography in Dee Rees' "Pariah" and Audre Lorde's "Zami: a new spelling of my name"', Journal of Lesbian Studies, vol. 20, no. 2, pp. 266-97.

Lorde, A 1982, Zami: a new spelling of my name, Persephone Press, London.

MacNeill, L 2012, 'There is no "I" in network: social networking sites and posthuman auto/biography', Biography, vol. 35, no. 1, pp. 65-82.

Nah, Y 2015, 'Rethinking the idiom for feminist pedagogy', Asian Journal for Women's Studies, vol. 21, no. 2, pp. 147-65.

Provost, K 1995, 'Afrekete: the trickster in the work of Audre Lorde', Society for the Study of the Multi-Ethnic Literature of the United States (MELUS), vol. 20, no. 4, pp. 45-59.

Rice, C 2009, 'Imagining the other? Ethical challenges of researching and writing women's embodied lives', Feminism \& Psychology, vol. 19, no. 2, pp. 245-66.

Rice, C, Chandler, E, Liddiard, K, Rinaldi, J, \& Harrison, E 2016, ‘Pedagogical possibilities for unruly bodies', Gender and Education, pp. 1-20. doi:10.1080/09540253.2016.1247947.

Rice, C 2017, 'Volatile bodies and vulnerable researchers: the risks of embodiment research', in SBatacharya \& R Wong (eds.), Embodiment, pedagogy and decolonization: critical and materialist considerations, Athabasca University Press, Edmonton.

Rice, C, Chandler, E \& Changfoot, N 2016, 'Imagining otherwise: the ephemeral spaces of envisioning new meanings', in C Kelly \& M Orsini (eds.), Mobilizing metaphor: 
art, culture and disability activism in Canada, University British Columbia Press, Vancouver, pp. 54-75.

Rice, C, Chandler, E, Harrison, E, Ferrari, M \& Liddiard, K 2014, 'Project re•vision: disability at the edges of representation', Disability \& Society, vol. 30, no. 4, pp. 513-27.

Rice, C, Chandler, E, Rinaldi, J, Liddiard, K \& Harrison, E 2016, 'Pedagogical possibilities for unruly bodies', Gender and Education, pp. 1-20. doi:10.1080/09540253.2016.1247947.

Rice, C \& Mundel, I forthcoming, 'Multimedia storytelling methodology: notes on access and inclusion in neoliberal times', Canadian Journal of Disability Studies.

Rogoff, I 2013, 'The expanded field, In JP Martinon, The curatorial: a philosophy of curating, Bloomsbury Publishing, London, pp. 41-8.

Ryan, S \& Runswick-Cole, L 2009, 'From advocate to activist? Mapping the experiences of mothers of children on the autism spectrum', Journal of Applied Research in Intellectual Disabilities, vol. 22, pp. 43-53.

Stacey, J 2000, 'Is academic feminism an oxymoron?' Signs: Journal of Women in Culture and Society, vol. 25, no. 4, pp. 1189-94.

Taber, N 2014, 'Tensions between practice and praxis in academia: adult education, neoliberalism, professional training, and militarism', The Canadian Journal for the Study of Adult Education, vol. 26, no. 2, pp. 9-20.

\section{Author information}

\section{Carla Rice}

Carla Rice, PhD, is Professor and Canada Research Chair at the University of Guelph. A leader in the field of embodiment studies and arts-informed research in Canada, her research explores cultural representations and stories of body, identity, and difference. She is founding director of Re•Vision: Centre for Art and Social Justice, a funded creative research program that works with misrepresented and aggrieved communities to advance social inclusion and justice through the arts. Notable books include Gender and Women's Studies in Canada: Critical Terrain (2013) and Becoming Women: The Embodied Self in Image Culture (2014). 


\section{Andrea LaMarre}

Andrea LaMarre, MSc., is a PhD candidate and Vanier Scholar in the Department of Family Relations and Applied Nutrition and a Research Affiliate at Re •Vision: Centre for Art and Social Justice at the University of Guelph. In her research, she uses qualitative and arts-informed research to explore the meaning of eating disorder recovery from the perspectives of diverse individuals, their supporters, and healthcare providers.

\section{Nadine Changfoot}

Nadine Changfoot, $\mathrm{PhD}$ is Associate Professor of Political Studies, Trent University, as well as a Senior Research Affiliate @ Re•Vision: Centre for Art and Social Justice. Her research is collaborative, addressing and producing art at the intersection of politics, arts activism, and community-campus engagement that include methods and ethics of research creation for multimedia storytelling and complex cross-sectoral partnerships that include the state, non-profit sector, aggrieved communities, and academy.

\section{Patty Douglas}

Patty Douglas, PhD, is Assistant Professor of Disability Studies in the Faculty of Education at Brandon University. She researches autism and care histories alongside lived experiences to speak back to exclusionary systems and enhance access to life. She is currently working on a monograph, Autism and Mothering: Ethical Disruptions and Care Pedagogies, which traces histories and lived experiences of autism and mothering to disrupt deficit representations of difference. 